\title{
Correction to: Training Courses in Laparoscopic Bariatric Surgery on Cadaver Thiel: Results of a Satisfaction Survey on Students and Professors
}

\author{
Jaime Ruiz-Tovar ${ }^{1}$ • Isabel Prieto-Nieto ${ }^{2}$ • Damián García-Olmo ${ }^{2}$ • Francisco Clascá ${ }^{3}$ - Pablo Enriquez ${ }^{4}$. \\ Ramon Vilallonga ${ }^{5} \cdot$ Lorea Zubiaga $^{6}$ \\ Published online: 1 July 2019 \\ (C) Springer Science+Business Media, LLC, part of Springer Nature 2019
}

\section{Correction to: Obesity Surgery \\ https://doi.org/10.1007/s11695-019-04003-2}

The name of author Ramon Vilallonga was misspelled in the original article. It is correct here.

Publisher's Note Springer Nature remains neutral with regard to jurisdictional claims in published maps and institutional affiliations.

The online version of the original article can be found at https://doi.org/ 10.1007/s11695-019-04003-2

Jaime Ruiz-Tovar

jruiztovar@gmail.com

1 Department of Surgery and Anatomy, Universidad Alfonso X, Avenida de la Universidad, 1, 28691 Villanueva de la Cañada, Madrid, Spain

2 Department of Surgery, Universidad Autónoma de Madrid, Madrid, Spain

3 Department of Anatomy, Universidad Autónoma de Madrid, Madrid, Spain

4 Department of Pathology and Surgery, Universidad Miguel Hernández, Alicante, Spain

5 Department of Surgery, Hospital Universitario Vall de Hebron, Barcelona, Spain

6 Centre Hospitalier Regionel Universitaire Lille, Lille, France 